\title{
The effects of physical and chemical preprocessing on the flowability of corn stover
}

\author{
Nathan C. Crawford ${ }^{\mathrm{a}, *}$, Nick Nagle ${ }^{\mathrm{a}}$, David A. Sievers ${ }^{\mathrm{a}}$, Jonathan J. Stickel ${ }^{\mathrm{a}}$ \\ ${ }^{a}$ National Bioenergy Center, National Renewable Energy Laboratory, Golden, CO, USA, \\ 80401
}

\begin{abstract}
Continuous and reliable feeding of biomass is essential for successful biofuel production. However, the challenges associated with biomass solids handling are commonly overlooked. In this study, we examine the effects of preprocessing (particle size reduction, moisture content, chemical additives, etc.) on the flow properties of corn stover. Compressibility, flow properties (interparticle friction, cohesion, unconfined yield stress, etc.), and wall friction were examined for five corn stover samples: ground, milled (dry and wet), acid impregnated, and deacetylated. The ground corn stover was found to be the least compressible and most flowable material. The water and acid impregnated stovers had similar compressibilities. Yet, the wet corn stover was less flowable than the acid impregnated sample, which displayed a flow index equivalent to the dry, milled corn stover. The deacetylated stover, on the other hand, was the most compressible and least flowable examined material. However, all of the tested stover samples had internal friction angles $>30^{\circ}$, which could present additional feeding and handling challenges. All of the "wetted" materials (water, acid, and deacetylated) displayed reduced flowabilities (excluding the acid impregnated sample), and enhanced compressibilities and wall friction angles, indicating the potential for added handling issues; which was corroborated via theoretical hopper design calculations. All of the "wetted" corn stovers require larger theoretical hopper outlet diameters and steeper hopper walls than the examined "dry" stovers.
\end{abstract}

Keywords: Biomass, Feedstock, Flowability, Shear, Rheology, Hopper

\footnotetext{
*Corresponding author. Tel.: +1 303-384-6215

Email address: nathan.crawford@nrel.gov (Nathan C. Crawford)
} 
design

\section{Abbreviations}

AICS, acid impregnated corn stover; DACS, deacetylated corn stover; GCS, ground corn stover; INL, Idaho National Laboratory; IR, infrared; MCS (dry), dry milled corn stover; MCS (wet), wet milled corn stover; NREL, National Renewable Energy Laboratory.

\section{Nomenclature}

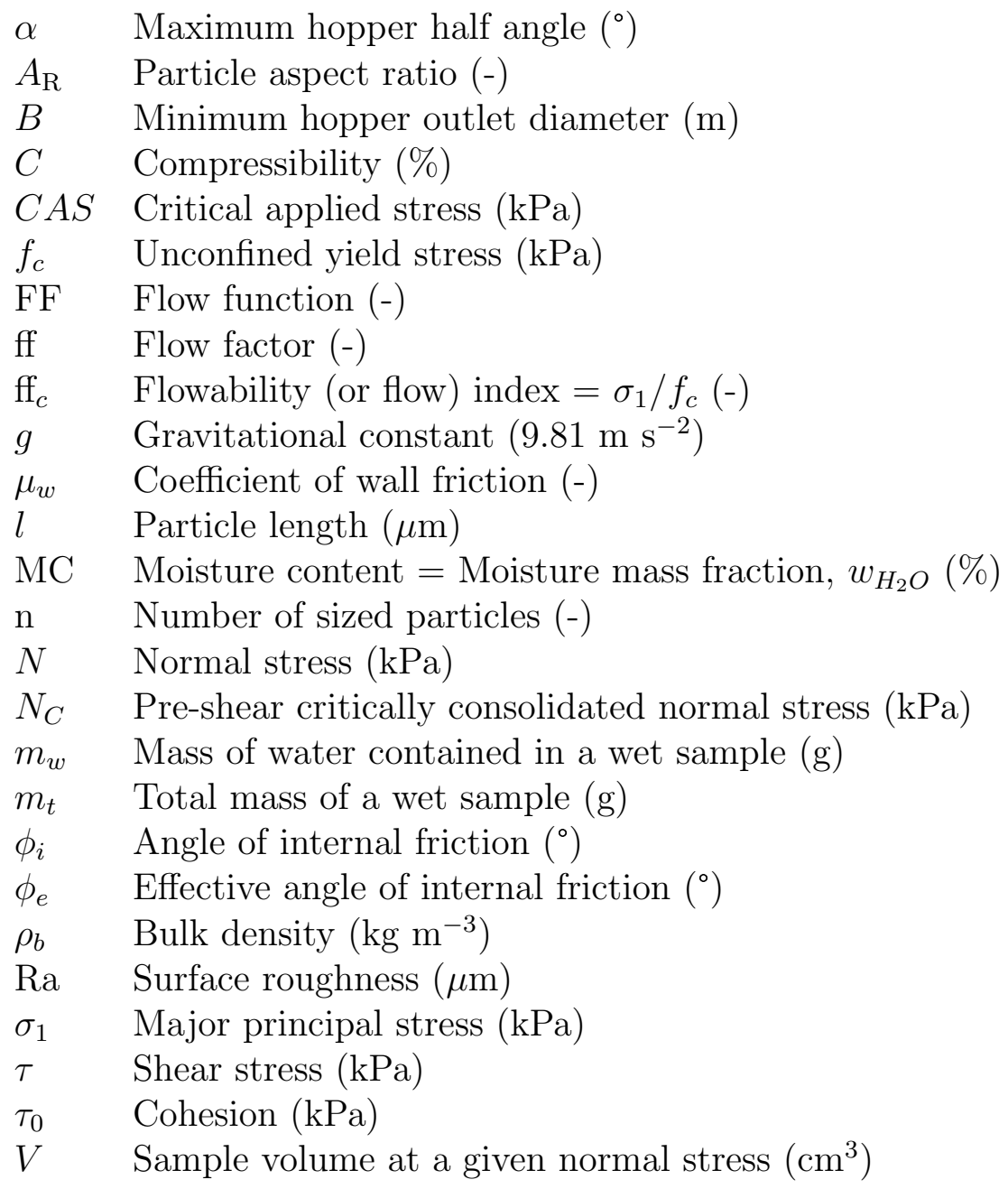


$V_{0} \quad$ Initial, conditioned sample volume $\left(\mathrm{cm}^{3}\right)$

$w \quad$ Particle width $(\mu \mathrm{m})$

\section{Introduction}

Continuous and stable biomass feeding is essential for successful operation of a biofuel production facility. Yet, solids feeding equipment commonly becomes jammed, bridged, or blocked with material, resulting in slowed reactor throughput and/or complete process interruption. Despite the significance of achieving uninterrupted feeding and the regularity of biomass feeding issues, more emphasis has been placed on the thermal, chemical, and biological deconstruction of biomass than on biomass handling problems. As a result, only a limited amount of information [1-3] has been published on the design and operation of biomass feeding systems.

Biomass feeding and handling is challenging for a variety of reasons. Biomass particles are inherently heterogeneous, varying greatly in size, shape, density, moisture content, and compressibility. Large particles, excessive moisture, and an insufficient (or too high) pressure differential between the feed hopper and reactor can all lead to feed system failure. In addition, feeders are commonly designed to handle a particular material under a specific set of preprocessing conditions (i.e., milling size, moisture content, chemical additive concentration, etc.). Minor alterations to the biomass, such as changes in moisture content or particle size, can significantly impact solids-handling systems. It is common for a feed system to work well for one material and completely fail for another with similar properties [4].

Further complicating this issue, biomass feedstocks are regularly preprocessed prior to entering reactor feed systems. Preprocessing can be fairly conventional, like milling to pass a certain screen size. However, preprocessing can also include chemical processing to enrich the biomass deconstruction process. Chemical additives not only increase the moisture content within the biomass, but they can potentially influence physical and chemical properties, and as a result, affect flowability.

Analyzing the flowability and physical properties of biomass is key to the design of efficient and effective biomass feeders [3]. Measuring biomass bulk density, compressibility, cohesion, internal friction, yield stress, and wall friction help determine a material's flowability and inform proper hopper design. However, only a limited number of studies have been published on the flowability of biomass and its impact on feed system design. Fasina [5] evaluated 
the affect of mill screen size on the compressibility and flowability of peanut hull, switchgrass, and poultry litter; while Chevanan et al. [6] designed, fabricated, and tested a direct shear cell to measure the shear strength and flow properties of chopped switchgrass, wheat straw, and corn stover. Zhou et al. [7] studied the affects of particle size and moisture content on particle density, bulk density, compressibility index, and porosity of two hybrid corn stovers, while Ileleji and Zhou [8] examined the effects of particle size and moisture content on the angle of repose of bulk corn stover. Samaniuk et al. [9] investigated the use of water soluble polymers as rheological modifiers to reduce the yield stress of wetted corn stover samples using a unique torque rheometer. Gil et al. [10], on the other hand, analyzed the effects of moisture content, particle size, and particle shape on the handling behavior of poplar and corn stover. Miccio et al. [11] studied the flow properties and tendency for arch formation of sawdust and ground olive husk using a ring shear apparatus and an arching tester. A recent study by Crawford et al. [12] evaluated the flowability of pure and blended biomass feedstocks, and linked the flow properties of the biomass materials to their pelleting energy requirements.

Although previous studies have investigated the effects of milling screen size and moisture content on the flow properties of various feedstocks, no study has specifically examined how preprocessing conditions, including chemical additives, affect the flowability of a single biomass species. In this manuscript, our objectives were to: 1) measure the compressibility and flow properties of corn stover under various processing conditions, 2) evaluate how moisture content, particle size, and chemical additives influence corn stover flowability, and 3) use the compressibility, shear cell, and wall friction measurements for theoretical hopper design calculations (see Section Appendix A for details) as a relative method to compare handling strategies for the preprocessed corn stover feedstocks.

\section{Materials and Methods}

\subsection{Materials}

Corn stover is a crop residue consisting of all portions of the plant left after corn grain harvest (the stock, stem, leafs, and cob). Corn stover is a desirable biofuel feedstock because it is not used as human or animal food, and large quantities are available as a byproduct of corn agriculture. The 

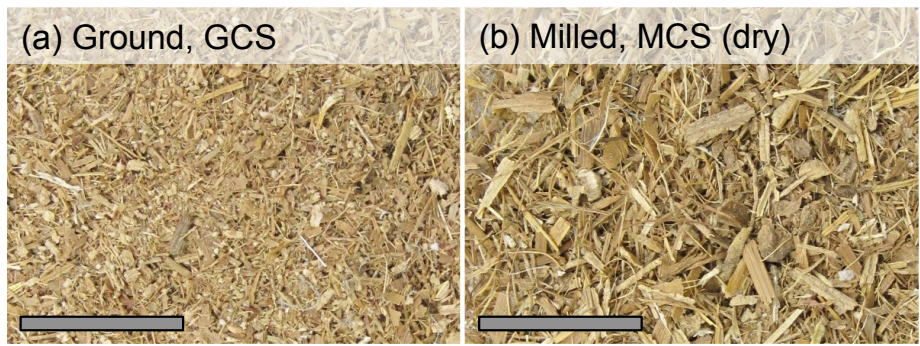

(c) Milled, MCS (wet)

(d) Acid Impregnated, AICS

(e) Deacetylated, DACS
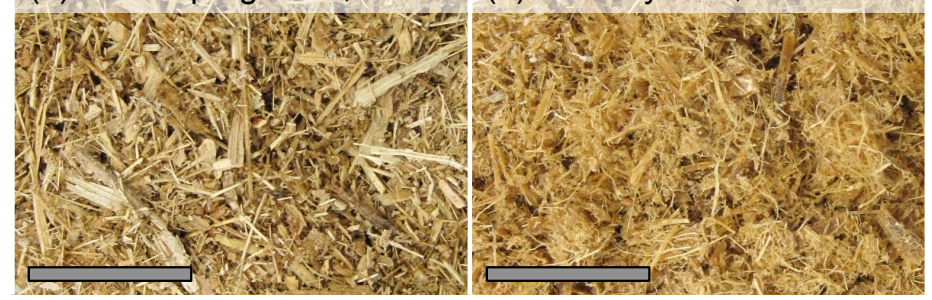

Figure 1: Digital images of the preprocessed corn stovers $($ scale bar $=2.54 \mathrm{~cm}$ ).

corn stover examined in this study was provided by Idaho National Laboratory (INL, Idaho Falls, ID, USA). All of the milling and/or grinding of the corn stover was performed by, or contracted out through, INL. The corn stover was single-pass harvested in Boone County, IA (USA) in the fall of 2011. However, detailed information on the chain of custody for this specific substrate was unavailable. Therefore, the cultivar cannot be specified and while the authors believe that this work illustrates the difference between preprocessing strategies, unknown substrate factors may have influenced the obtained results.

All chemical processing or wetting of the stover was performed at the National Renewable Energy Laboratory. The following subsections describe the preprocessing conditions for the five tested corn stover samples.

\subsubsection{Ground}

Bales of corn stover were fed through a two-stage, full-scale grinding process using the Feedstock Process Demonstration Unit (PDU) as part of DOE's Biomass Feedstock National User Facility (BFNUF) located at Idaho National Laboratory (Idaho Falls, ID, USA). First, material was processed through a Vermeer BG-480 (Pella, IA, USA), which has two horizontal grinding drums with swinging hammers powered by two, $149 \mathrm{~kW}$ motors [13], and passed through a $5 \mathrm{~cm}$ screen. Then, the $5 \mathrm{~cm}$ screened material was pro- 
cessed through a Bliss hammer mill (Ponca City, OK, USA) with a $6.35 \mathrm{~mm}$ screen. The ground corn stover (GCS) sample was prepared for a separate feedstock pelleting study.

\subsubsection{Milled (dry)}

Baled corn stover was milled in a single-stage milling process using a Bliss hammer mill equipped with a $6.35 \mathrm{~mm}$ screen. The dry milled corn stover (MCS (dry)) sample was used as the base feedstock for the remaining corn stover samples (wet milled, acid impregnated, and deacetylated).

\subsubsection{Milled (wet)}

DI water was added to a subsample of MCS (dry) material to a target moisture mass fraction of $50 \%$. The "wet" milled corn stover (MCS (wet)) sample was saturated to $50 \%$ total solids in order to match the moisture contents of the following preprocessed corn stover materials (acid impregnated and deacetylated).

\subsubsection{Acid Impregnated}

The dry milled corn stover was soaked with a $2.0 \%$ mass fraction sulfuric acid $\left(\mathrm{H}_{2} \mathrm{SO}_{4}\right)$ in water solution at a total mass fraction of solids of $8 \%$ for 2 hours. The acid impregnated corn stover (AICS) slurry was then transferred to a continuous screw press (Vincent Corporation, Model CP10, Tampa, FL, USA) to remove excess liquor and achieve a target moisture mass fraction of $\sim 50 \%$. The selected acid impregnation conditions correspond with pilotscale dilute acid pretreatment for the biochemical conversion of lignocellulosic biomass to biofuels $[14,15]$.

\subsubsection{Deacetylated}

Dry milled corn stover was soaked in a $0.4 \%$ mass fraction of sodium hydroxide $(\mathrm{NaOH})$ in water solution at a total solids mass fraction of $8 \%$. The corn stover slurry was mixed continuously at $80^{\circ} \mathrm{C}$ for 2 hours. The slurry was drained overnight, allowing the free-liquid fraction to be removed. The corn stover solids were then washed in DI water $(10 \%$ mass fraction of solids) and mixed for 1 hour. Again, the free-liquid was removed via draining. The washed corn stover solids were then dilute acid impregnated with $0.8 \%$ mass fraction of $\mathrm{H}_{2} \mathrm{SO}_{4}$ in water at a total solids mass fraction of $8 \%$ and thoroughly mixed at ambient conditions for 2 hours. The deacetylated and acid treated corn stover (DACS) was then pumped to a continuous screw 
press to remove excess free-liquid and achieve a total mass fraction of corn stover solids of 45 to $50 \%$. The chosen deacetylation conditions correspond with the State of Technology for pilot-scale deacetylation preprocessing for the biochemical conversion of lignocellulosic biomass to biofuels [16].

\subsection{Moisture Content}

The moisture contents of the preprocessed corn stover samples were determined using a semi-automated infrared (IR) balance (Mettler Toledo, model HR83 Halogen, Columbus, OH, USA). The IR balance has two separate operating procedures designed specifically for measuring the dry matter content of both wet and "dry" biomass feedstock samples. The oven operated at a maximum temperature of $105{ }^{\circ} \mathrm{C}$ and dried the corn stover samples until less than $0.01 \%$ change in dry matter content was detected over a 1 min interval. Moisture content (MC) was reported as the percent mass fraction of water $\left(w_{\mathrm{H}_{2} \mathrm{O}}\right)$ per the total wet mass of the sample. Sample size ranged from 0.5 to $1.0 \mathrm{~g}$, and the samples were evenly distributed across the drying pan. All moisture content measurements were repeated in triplicate and measurement variability was reported as a single standard deviation.

\subsection{Microscopy}

Particle size parameters for the preprocessed corn stover samples were obtained using optical microscopy and quantitative image analysis (Leica DM 3000, Clemex Technologies Inc., Longueuil, Quebec, Canada; data analysis via Clemex Vision PE software, version 6). The optical micrographs not only allowed for sizing of the corn stover materials (particle length and width), but also particle dimensional analysis, namely aspect ratio. Particle dimensions of individual particles were measured and categorized into geometrically spaced bins ranging from 25 to $55,500 \mu \mathrm{m}$ for length (20 total bins) and 25 to $5,000 \mu \mathrm{m}$ for width (14 total bins), which provided full particle length and width distributions. The particle length and width histograms were reported on a number basis, while average particle dimensions were computed on a volume basis $[17,18]$. Number based dimensional analysis was avoided due to the high number of fine particles quantified via microscopy, which biases average particle dimensions towards smaller values. In addition, analyzing microscopy results on a volume basis allows for a more direct comparison between other commonly used biomass sizing techniques (i.e., laser diffraction and sieving). 


\subsection{Powder Rheometer}

The FT4 Powder Rheometer (Freeman Technology, Worcestershire, UK) was used to measure the flow properties of the preprocessed corn stover feedstocks. The FT4 Powder Rheometer is a comprehensive powder tester, capable of measuring compressibility and rotational shear properties, including wall friction. A full description of the FT4's capabilities can be found elsewhere $[19,20]$.

Testing was performed with the $50 \mathrm{~mm}$ diameter, borosilicate test vessel (85 $\mathrm{cm}^{3}$ test volume). Prior to all testing, samples were conditioned using the $23.5 \mathrm{~mm}$ blade to standardize the packing state of each sample (larger diameter blades were avoided because the biomass particles became entangled with the blade leading to a torque overload). The conditioning step consisted of an axial traverse of the blade downward and upward through the full height of the sample. During the upward traverse, the blade lifts the particles and lightly drops them behind the blade. Conditioning aerates and loosens the granular sample, removing any trapped air and/or any pre-consolidation that may have occurred during filling of the vessel.

All test methodologies, compressibility, shear cell, and wall friction, were repeated in triplicate (at minimum) to assess measurement variability, with all error bars reported as a single standard deviation.

\subsubsection{Compressibility}

The compressibility test involved the compression of a preconditioned sample bed with a vented piston which permits entrained air to escape. Each sample was slowly compacted across a range of normal stresses $(N)$ from 0.5 to $21 \mathrm{kPa}$, the change in bed height was measured at 11 distinct intervals. The compressibility of a sample $(C)$ is defined as the percent change in volume after compression, $C=\left(V_{0}-V\right) / V_{0}$; where $V_{0}$ is the initial, conditioned volume and $V$ is the volume at a specific normal stress value.

\subsubsection{Shear Cell}

Shear cell testing was executed with the $48 \mathrm{~mm}$ shear head in the normal force control mode, so as the shear head was rotated, torque was measured while the normal force remained constant (i.e., the shear head displaced vertically during testing). During the shear cell test, the sample was first compacted with the vented piston to a specific pre-shear normal load $(3,6$, 9 , or $15 \mathrm{kPa}$ ). After compaction, the piston was removed and the shear head was attached. The shear head was then lowered and its blades were inserted 
into the sample until the pre-shear normal force was again achieved. The head was then slowly rotated at $5 \mathrm{mrad} \mathrm{s}^{-1}$, inducing a shear stress. The sample was sheared continuously until the shear stress reached steady state, whereupon the sample was considered "critically consolidated" [21]. Next, the normal stress was reduced, which allowed room for the particles to distend and move past one another. At that point, a yield stress could be measured. The pre-shear/shear sequence was repeated five times (as recommended by Carson and Wilms [22]) at decreasing normal stress values (the sample was always pre-sheared to the critically consolidated state prior to measurement). A plot of the normal stress and shear stress pairings was then attained, referred to as the yield locus. Yield loci are unique and contingent upon the pre-shear history of the sample. Each yield locus was independently evaluated using Mohr stress circle analysis to obtain values of: the major and minor principal stresses, unconfined yield stress, cohesion, and interparticle friction, as described by Carson and Wilms [22] and Freeman [19].

In order to characterize a material's flowability, Jenike [21] proposed using the ratio of the major principal stress to the unconfined yield stress, called the flowability index $\left(\mathrm{ff}_{c}\right)$. Based on the flow index value, materials can be classified as non-flowing, very cohesive, cohesive, easy flowing, or free flowing $[23]$.

\subsubsection{Wall Friction}

Wall friction properties are essential for understanding how a consolidated granular material will interact with the wall material of a storage vessel or processing equipment. Wall friction tests are similar to shear cell testing. Instead of shearing the sample against itself (acquiring properties like interparticle friction or cohesion), the wall friction test shears the sample along a disc of material with well defined surface properties. Essentially, the shear head was replaced with a $48 \mathrm{~mm}$ stainless steel coupon (316 grade, surface roughness, $\mathrm{Ra}=1.2 \mu \mathrm{m})$. During wall friction tests, the samples were compacted and pre-sheared at a given normal stress $(3,9$, or $15 \mathrm{kPa})$. As with the shear cell test, the normal force was decreased and the sample was sheared until a maximum shear stress was reached (i.e., a wall yield stress was measured). The shear stress and normal force pairs were then plotted to obtain a wall friction yield locus. Wall friction coefficients, or angles, were then extracted from the loci. Given that the structural integrity of the sample was not destroyed during shearing, the wall friction test requires only one pre-shear step and five successive shear steps. 


\section{Results and Discussion}

\subsection{Particle Morphology}

The particle size distributions of the ground and milled corn stover (GCS and MCS (dry), respectively) appear to be significantly different (Figure $2 \mathrm{a}$ and $\mathrm{b}$ ). The MCS (dry) material has a much broader particle length distribution with $\sim 35 \%$ of its particles longer than $1000 \mu \mathrm{m}$. The GCS material, on the other hand, has a narrower particle length distribution with only $\sim 5 \%$ of its particles longer than $1000 \mu \mathrm{m}$ (Figure 2a). The particle width distributions for the ground and milled corn stover are fairly similar, but the MCS (dry) sample still has significantly more wide particles. The MCS (dry) material has $\sim 20 \%$ of its particles wider than $300 \mu \mathrm{m}$, while the GCS feedstock has only $\sim 8 \%$ of its particles wider than $300 \mu \mathrm{m}$ (Figure 2 ). The large fraction of long particles found in the MCS (dry) sample are a direct result of milling conditions. The MCS (dry) feedstock was just hammer milled to a $6.35 \mathrm{~mm}$ screen size, while the GCS material was first ground and then hammer milled using a $6.35 \mathrm{~mm}$ screen. The grinding process used to generate the GCS material was more effective at eliminating large particles and producing a more uniform size distribution.

The volume-averaged particle lengths of all the materials are provided in Table 2. Again, the GCS material was much smaller than the other examined corn stover samples. Although the milled and chemically processed samples (MCS dry and wet, AICS, and DACS) have slightly different particle lengths (especially the AICS sample), the large variance in the particle length values keep them from being statistically different from one another. In addition, the milled and chemically treated corn stover materials also have similar particle widths that are significantly larger than the ground corn stover sample (Table 2).

The average aspect ratio (defined as the length to width ratio) was between 9 to 14 for all four of the milled and/or treated corn stover feedstocks, with large maximum measured aspect ratios of $\sim 80$ to 190 (parentheses in Table 2). However, the GCS material had an aspect ratio of $\sim 4$ with a maximum value of $\sim 26$. Once again, the ground corn stover feedstock was more uniform in shape and appeared to be devoid of multiple large, string-like particles that bias the particle aspect ratio towards larger values.

Overall, the milled and chemically treated corn stover samples (MCS dry and wet, AICS, and DACS) have nearly identical particle sizes (length and width) and size distributions, and fairly similar aspect ratios. The MCS dry 

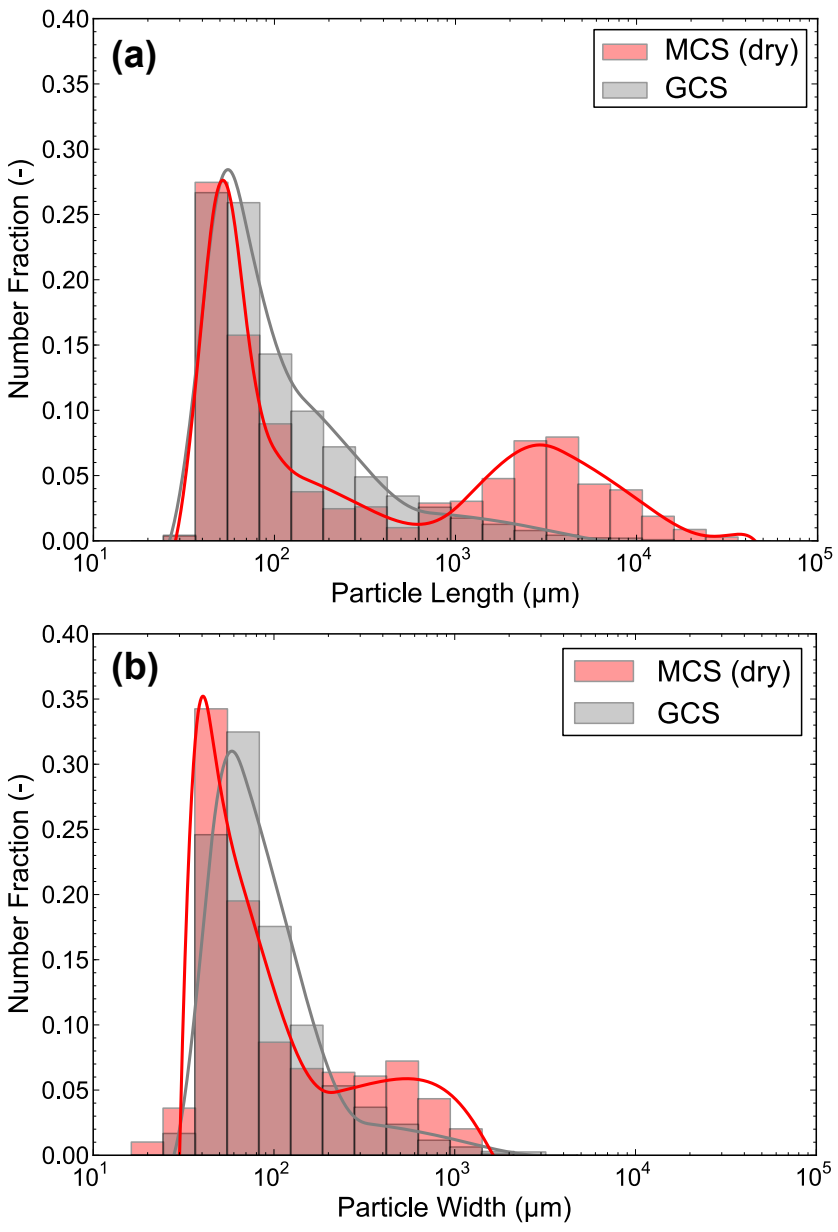

Figure 2: Geometric particle (a) length and (b) width distributions for ground and milled corn stover (GCS and MCS (dry), respectively) using optical microscopy. The solid lines are from a cubic interpolation function to help guide the eye. 
Table 2: Moisture content (MC) and volume average particle dimensions of the preprocessed corn stovers via optical microscopy $(\mathrm{n}=$ the number of particles sized, $l=$ particle length, $w=$ particle width, and $A_{\mathrm{R}}=$ aspect ratio). The " \pm " indicates a single standard deviation, while the parentheses denote a maximum measured aspect ratio.

\begin{tabular}{ccccccc}
\hline Corn stover & Abbreviation & $\begin{array}{c}\text { MC } \\
(\%)\end{array}$ & $\begin{array}{c}\mathrm{n} \\
(-)\end{array}$ & $\begin{array}{c}l \\
(\mu \mathrm{m})\end{array}$ & $\begin{array}{c}w \\
(\mu \mathrm{m})\end{array}$ & $\begin{array}{c}\mathrm{A}_{\mathrm{R}} \\
(-)\end{array}$ \\
\hline \hline Ground & GCS & $6.7 \pm 0.6$ & 4432 & $1668 \pm 901$ & $257 \pm 97$ & $4.3(26)$ \\
\hline $\begin{array}{c}\text { Milled } \\
(\text { dry })\end{array}$ & MCS (dry) & $5.2 \pm 0.2$ & 692 & $6205 \pm 3218$ & $424 \pm 295$ & $9.0(171)$ \\
\hline $\begin{array}{c}\text { Milled } \\
(\text { wet })\end{array}$ & MCS (wet) & $49.9 \pm 0.5$ & 460 & $6097 \pm 2897$ & $433 \pm 230$ & $11.3(86)$ \\
\hline $\begin{array}{c}\text { Acid } \\
\text { Impregnated }\end{array}$ & AICS & $50.8 \pm 1.1$ & 1802 & $4615 \pm 1534$ & $480 \pm 194$ & $11.6(81)$ \\
\hline Deacetylated & DACS & $44.8 \pm 0.8$ & 2165 & $5960 \pm 1728$ & $296 \pm 205$ & $13.5(190)$ \\
\hline
\end{tabular}

and wet, AICS, and DACS materials differ only by moisture content and chemical additive. Therefore, differences in their compressibility and flowability should be a direct result of their moisture content and/or chemical processing history, and not due to differences in particle size or shape. The ground corn stover feedstock (GCS), on the other hand, has much smaller particles, more narrow particle length and width distributions, and a more uniform particle shape (as described by the aspect ratio). Thus, any potential differences in the compressibility and flowability of the GCS feedstock will most likely be due to its reduced particle size and increased particle homogeneity (particularly when compared to the MCS (dry) sample).

\subsection{Compressibility}

Compressibility is a bulk property that quantifies a material's propensity to become compacted when subjected to a normal force. The compressibility measurement is not a direct evaluation of flowability, but it can reveal the strength of adhesive forces between particles (which are inversely related to flowability). For example, poor flowing bulk solids typically have strong interparticle adhesive forces, which creates large voids within the particle network. These large voids will collapse under compression, leading to increased material compressibility. Therefore, it is anticipated that highly compressible bulk solids will also be poor flowing.

The compressibilities of the preprocessed corn stover feedstocks were as- 


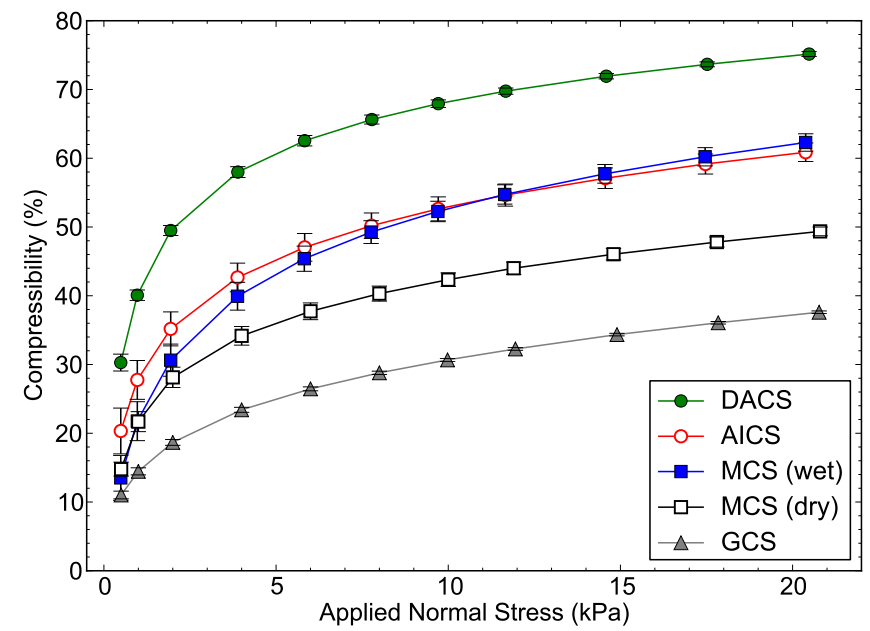

Figure 3: Compressibility (\% change in volume) of the preprocessed corn stovers as a function of applied normal stress.

sessed from 0.5 to $21 \mathrm{kPa}$ (Figure 3). The DACS sample was by far the most compressible, compressing by over $75 \%$ at $21 \mathrm{kPa}$ (Figure 3). The AICS and MCS (wet) materials were less compressible and exhibited nearly identical compressibilities (both compressing to $\sim 62 \%$ at $21 \mathrm{kPa}$ ); while the dry MCS sample was even less compressible, compressing by $49 \%$ at $21 \mathrm{kPa}$. The GCS feedstock was the least compressible, compressing only $38 \%$ at $21 \mathrm{kPa}$.

The additional compressibility of the deacetylated corn stover was most likely due to the alkaline soaking step in the deacetylation process (see Section 2.1.5 for details), especially since the acid impregnated material was less compressible than the DACS sample. Alkaline treatment is used in biomass processing to remove acetyl groups from hemicellulose [24, 25] and to partially solubilize lignin $[26,27]$, a complex biopolymer responsible for giving strength to the secondary cell wall in most terrestrial plants. Treating with $\mathrm{NaOH}$ has been reported to swell lignocellulosic biomass (leading to increased internal surface area) [26-29], as well as decrease its crystallinity [26, 28, 29], disrupt the structure of lignin [26-29], and break bonds between hemicellulose and lignin [29]. If a portion of the lignin in the DACS sample was solubilized or disrupted, then the internal structure of the corn stover would be weakened, making it more flexible and more susceptible to collapse under compression. In addition, alkaline preprocessing could also alter the sur- 
face chemistry of the corn stover particles; making them more adhesive (or "sticky"), which would also enhance its compressibility (as discussed above). However, qualitatively, the DACS particles appeared much more flexible and "fluffy" in comparison to the other preprocessed corn stover materials.

In contrast, acid impregnation of corn stover does not appear to greatly affect its internal structure or surface chemistry (unlike the deacetylation process). The AICS material was more compressible than the MCS (dry) sample, but was equally as compressible as the MCS (wet) material. Therefore, the increase in compressibility via acid impregnation seems to be a result of increased moisture content and not a consequence of acid-aided physical or chemical alteration. The AICS and MCS (wet) feedstocks both had moisture contents of $\sim 50 \%$, while the MCS (dry) material had a moisture content of only $\sim 7 \%$ (Table 2). Increased moisture can lead to a "softening" of the biomass and act a lubricant during compaction, both resulting in enhanced compressibility.

However, all four of the milled and treated corn stover feedstocks (including the MCS (dry) material) were more compressible than the ground corn stover. The increased compressibility of the milled materials was most likely due to their higher fraction of large particles. The large particles in the MCS (dry and wet), AICS, and DACS samples generate collapsible void spaces within the solids network. During compaction, smaller particles rearrange and fill in the void spaces surrounding the larger particles [5, 30]. As a result, materials with broader size distributions are typically more compressible $[5,31]$.

\subsection{Shear Testing}

The yield stress values for the five preprocessed feedstocks, GCS, MCS (wet and dry), AICS, and DACS, at a pre-shear normal stress value of $9 \mathrm{kPa}$, decreased with decreasing normal stress (Figures 4a and b). The MCS (wet) and DACS materials displayed relatively high, yet similar, yield strengths, cohesion, and interparticle friction (Figure 4a). The MCS (dry) and AICS feedstocks, on the other hand, had slightly lower, but similar, yield stress, cohesion, and interparticle friction values; whereas the GCS material had the lowest yield stress values, as well as the lowest interparticle cohesion and friction (Figure 4b).

Using Mohr circle analysis, the yield loci from Figures $4 \mathrm{a}$ and $\mathrm{b}$ can be extrapolated to produce values of the unconfined yield stress $\left(f_{c}\right)$ and the major principal stress $\left(\sigma_{1}\right)$. Plotting $f_{c}$ as a function of $\sigma_{1}$ generates a 

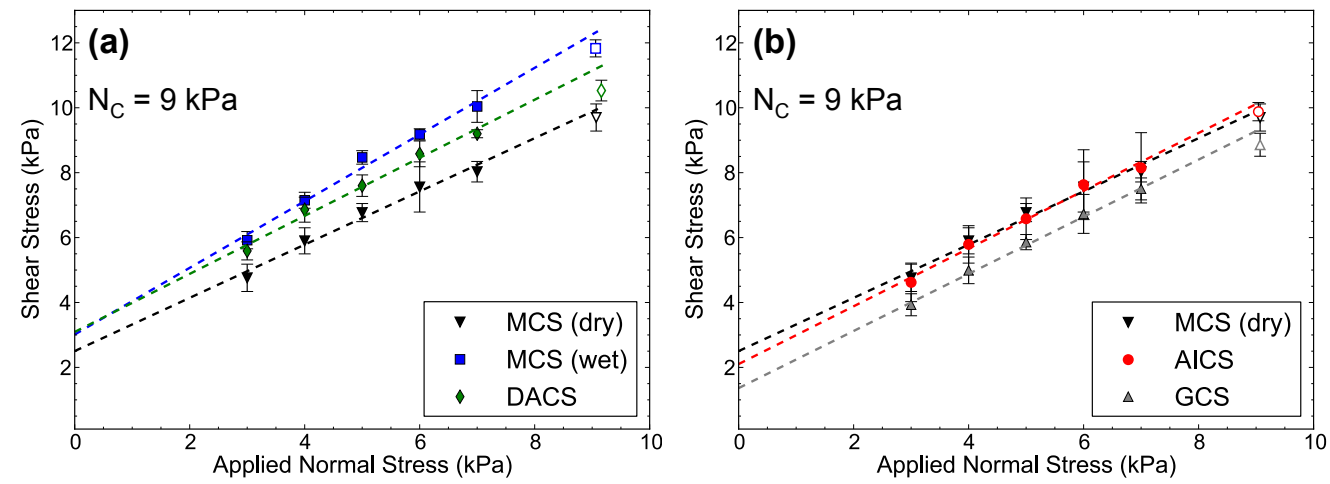

Figure 4: Steady shear stress (open symbols) and yield stress (filled symbols) at a consolidation normal stress $\left(N_{C}\right)$ of $9 \mathrm{kPa}$ as a function of applied normal stress for: (a) MCS (dry and wet) and DACS and (b) MCS (dry), AICS, and GCS (MCS (dry) was plotted on both figures for reference). The dashed lines are linear fits to the yield stress data $\left(\mathrm{R}^{2}\right.$ $>0.98$ for all fits).

linearized relationship, deemed the flow function. The inverse of the flow function slope is referred to as the flowability index $\left(\mathrm{ff}_{c}\right)$. Moving from the bottom-right to the upper-left corner in Figure 5, the values of the flowability index decrease from the free flowing region to the non-flowing regime.

The flow functions for all of the preprocessed corn stover feedstocks yielded linear increases in $f_{c}$ with increasing $\sigma_{1}$ (Figure 5); with MCS (dry) and AICS both falling in the cohesive flow regime. Alternatively, DACS and MCS (wet) had flow indices categorized as very cohesive; while GCS was the most flowable material with a flow function in the easy flowing region. Flowability of a material is dependent on its physical properties, as well as the environmental conditions and the equipment used for handling, storing, and processing [32]. Both adding water and deacetylating the milled corn stover lead to a reduction in flowability. Interestingly, acid impregnating the corn stover did not significantly alter its flowability. However, reducing the particle size and narrowing the size distribution via grinding, enhanced the flowability of corn stover.

A summary of all flowability parameters, including: static and effective angles of interparticle friction $\left(\phi_{i}\right.$ and $\phi_{e}$, respectively), cohesion $\left(\tau_{0}\right)$, unconfined yield stress $\left(f_{c}\right)$, and major principal stress $\left(\sigma_{1}\right)$ for pre-shear normal stress $\left(N_{C}\right)$ values of 3 to $15 \mathrm{kPa}$ are reported in Table 3 . In general, the cohesive strengths and unconfined yield stresses of the MCS (wet) and DACS 


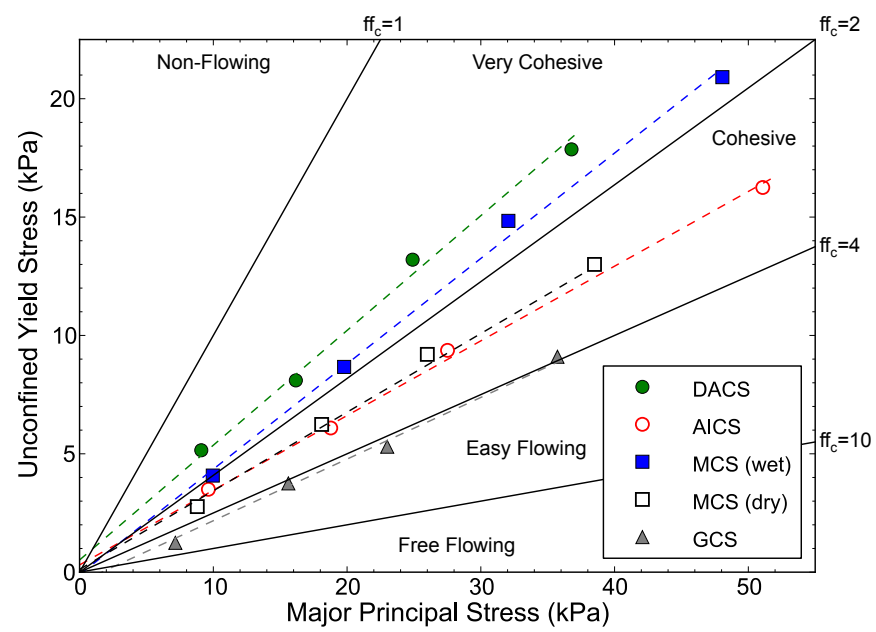

Figure 5: Unconfined yield stress versus major principal stress for the preprocessed corn stover feedstocks. The solid lines represent the boundaries between flowability designations, while the dashed lines are linear fits to the individual data sets.

materials were found to be the highest; while MCS (dry) and AICS both had slightly lower cohesion and unconfined yield stress values. The GCS sample, on the other hand, had significantly lower values of both cohesion and unconfined yield stress. All of the preprocessed stovers had internal friction angles greater than $30^{\circ}$. Commonly, bulk materials with interparticle cohesion less than $2 \mathrm{kPa}$ and internal friction angles less than $30^{\circ} \mathrm{can}$ be handled using gravity alone [6,33]. Unfortunately, it appears that all of the examined preprocessed stovers will present challenges during the feeding, passage, and discharge of process vessels.

The measured flow indices $\left(\mathrm{ff}_{c}\right)$ of the preprocessed corn stover samples ranged from 1.7 to 6.2. The ground corn stover (GCS) had a $\mathrm{ff}_{c}$ of $5.0 \pm 0.8$, which was the largest flow index for all of the examined corn stovers and classifies GCS as an "easy flowing" material. The MCS (dry) and AICS displayed identical $\mathrm{ff}_{c}$ values of $3.0 \pm 0.4$ and $3.0 \pm 0.3$, respectively; designating them both as "cohesive" materials. The MCS (wet) had an average flow index of $2.2 \pm 0.2$, which was slightly lower than the $\mathrm{ff}_{c}$ for MCS (dry) and AICS, but still classifies MCS (wet) as "cohesive." Conversely, the DACS sample had the smallest flow index at $1.9 \pm 0.2$, which places the deacetylated material in the "very cohesive" regime.

There is a limited archive of literature reporting on the flowability pa- 
Table 3: Shear testing results for the preprocessed corn stover feedstocks at pre-shear normal stress $\left(N_{C}\right)$ values of $3,6,9$, and $15 \mathrm{kPa}$ (static and effective angles of interparticle friction $\left(\phi_{i}\right.$ and $\phi_{e}$, respectively), cohesion $\left(\tau_{0}\right)$, unconfined yield stress $\left(f_{c}\right)$, and major principal stress $\left.\left(\sigma_{1}\right)\right)$. The " \pm " indicates a single standard deviation.

\begin{tabular}{|c|c|c|c|c|c|c|}
\hline Material & $\begin{array}{c}N_{C} \\
(\mathrm{kPa})\end{array}$ & $\begin{array}{l}\phi_{i} \\
\left(^{\circ}\right)\end{array}$ & $\begin{array}{l}\phi_{e} \\
\left(^{\circ}\right)\end{array}$ & $\begin{array}{c}\tau_{0} \\
(\mathrm{kPa})\end{array}$ & $\begin{array}{c}f_{C} \\
(\mathrm{kPa})\end{array}$ & $\begin{array}{c}\sigma_{1} \\
(\mathrm{kPa})\end{array}$ \\
\hline \multirow{4}{*}{ GCS } & 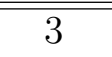 & 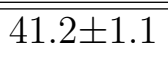 & $45.2 \pm 0.2$ & 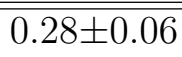 & $1.2 \pm 0.2$ & $7.2 \pm 0.1$ \\
\hline & 6 & $41.3 \pm 0.7$ & $46.8 \pm 0.6$ & $0.85 \pm 0.07$ & $3.8 \pm 0.3$ & $15.6 \pm 0.9$ \\
\hline & 9 & $41.6 \pm 1.3$ & $47.8 \pm 2.0$ & $1.36 \pm 0.30$ & $5.3 \pm 0.3$ & $23.3 \pm 0.5$ \\
\hline & 15 & $40.9 \pm 0.8$ & $48.0 \pm 1.1$ & $2.50 \pm 0.32$ & $9.1 \pm 0.5$ & $35.7 \pm 1.8$ \\
\hline \multirow{4}{*}{ MCS (dry) } & 3 & $46.5 \pm 1.6$ & $53.5 \pm 1.3$ & $0.55 \pm 0.05$ & $2.8 \pm 0.3$ & $8.8 \pm 0.2$ \\
\hline & 6 & $42.4 \pm 2.3$ & $51.4 \pm 2.7$ & $1.42 \pm 0.20$ & $6.2 \pm 0.3$ & $18.1 \pm 0.9$ \\
\hline & 9 & $39.2 \pm 3.7$ & $49.8 \pm 2.5$ & $2.50 \pm 0.59$ & $9.2 \pm 1.0$ & $26.0 \pm 0.6$ \\
\hline & 15 & $40.1 \pm 4.5$ & $50.6 \pm 3.8$ & $3.78 \pm 1.40$ & $13.0 \pm 3.7$ & $38.5 \pm 4.8$ \\
\hline \multirow{4}{*}{ MCS (wet) } & 3 & $48.6 \pm 3.2$ & $58.5 \pm 3.9$ & $0.79 \pm 0.09$ & $4.1 \pm 0.9$ & $10.0 \pm 0.7$ \\
\hline & 6 & $46.5 \pm 2.8$ & $57.7 \pm 1.9$ & $1.64 \pm 0.26$ & $8.7 \pm 1.0$ & $19.8 \pm 1.8$ \\
\hline & 9 & $45.2 \pm 3.0$ & $57.3 \pm 1.1$ & $3.01 \pm 0.35$ & $14.8 \pm 0.6$ & $32.1 \pm 1.7$ \\
\hline & 15 & $46.7 \pm 2.5$ & $56.8 \pm 4.2$ & $4.12 \pm 0.53$ & $20.7 \pm 0.8$ & $47.7 \pm 1.3$ \\
\hline \multirow{4}{*}{ AICS } & 3 & $47.8 \pm 1.7$ & $56.1 \pm 2.3$ & $0.66 \pm 0.09$ & $3.5 \pm 0.4$ & $9.6 \pm 0.3$ \\
\hline & 6 & $45.6 \pm 4.0$ & $56.1 \pm 2.9$ & $1.82 \pm 0.18$ & $6.1 \pm 0.5$ & $18.8 \pm 1.1$ \\
\hline & 9 & $47.7 \pm 3.1$ & $56.8 \pm 3.5$ & $2.10 \pm 0.36$ & $9.4 \pm 2.7$ & $27.5 \pm 3.3$ \\
\hline & 15 & $50.4 \pm 3.1$ & $61.4 \pm 0.8$ & $4.69 \pm 1.41$ & $16.3 \pm 5.6$ & $51.1 \pm 4.5$ \\
\hline \multirow{4}{*}{ DACS } & 3 & $45.7 \pm 2.6$ & $60.0 \pm 3.2$ & $1.05 \pm 0.17$ & $5.2 \pm 1.1$ & $9.1 \pm 1.1$ \\
\hline & 6 & $44.0 \pm 3.3$ & $56.6 \pm 1.8$ & $1.71 \pm 0.12$ & $8.1 \pm 0.6$ & $16.2 \pm 1.7$ \\
\hline & 9 & $41.8 \pm 1.5$ & $56.4 \pm 1.2$ & $3.09 \pm 0.42$ & $13.2 \pm 1.5$ & $24.9 \pm 1.0$ \\
\hline & 15 & $39.3 \pm 6.5$ & $52.5 \pm 5.6$ & $4.20 \pm 0.45$ & $17.8 \pm 2.1$ & $36.4 \pm 2.7$ \\
\hline
\end{tabular}


rameters of corn stover. Chevanan et al. [6] used a custom fabricated linear shear box to determine the flow properties of chopped corn stover. They reported $\phi_{i}$ values of $46-50^{\circ}$ and $\mathrm{ff}_{c}$ values of 2.2-3.4, respectively, for corn stover. Gil et al. [10], on the other hand, used a Jenike shear device to measure the flowability of corn stover milled to target particle sizes of 2 and $5 \mathrm{~mm}$ with varying moisture contents (7-33\%). They reported $\phi_{i}$ and $\mathrm{ff}_{c}$ values of $26-33^{\circ}$ and 3.6-10.1 for corn stover. It was difficult to make a direct comparison between these past studies and our current work due to the different shearing devices used and the fact that no two corn stover samples are alike. However, the flow properties reported here for the preprocessed corn stover materials are still in agreement with this limited set of literature values.

\subsection{Wall Friction}

Wall friction testing involves measuring a wall yield locus, which describes the shear stress required to move granular solids continuously across a wall surface under a specified normal stress. From the wall yield loci, wall friction angles (or coefficients) can be determined.

The measured angles of wall friction (at a surface roughness, Ra, of 1.2 $\mu \mathrm{m}$ ) for the preprocessed corn stover materials ranged from 10 to $32^{\circ}$ (Figure $6)$. The two dry corn stover feedstocks, GCS and MCS (dry), both had wall friction angles of $\sim 10^{\circ}$. A wall friction angle of $10^{\circ}$ (denoted with a dashed line in Figure 6) is considered relatively low, indicating that the dry feedstocks should not experience discharge problems due to material wall binding. The AICS and DACS materials, on the other hand, displayed wall friction angles of $\sim 23^{\circ}$; which are significant enough to lead to material holdup issues during vessel discharge. The MCS (wet) sample exhibited a wall friction angle of $\sim 32^{\circ}$. An angle of wall friction $\geq 30$ (dashed line in Figure 6) signifies a high potential for material binding to vessel walls during discharge. As a result, the "wetted" corn stover samples (MCS (wet), AICS, and DACS), may present additional handling issues due to their moderate-to-high affinity to bind to wall surfaces.

\subsection{Hopper Design}

Jenike's hopper design methodology (see Section Appendix A for details) was used to estimate the maximum hopper half angle $(\alpha)$ and minimum hopper opening diameter $(B)$ for mass flow in a conical hopper for each preprocessed corn stover sample. Measured values of bulk density as a function 


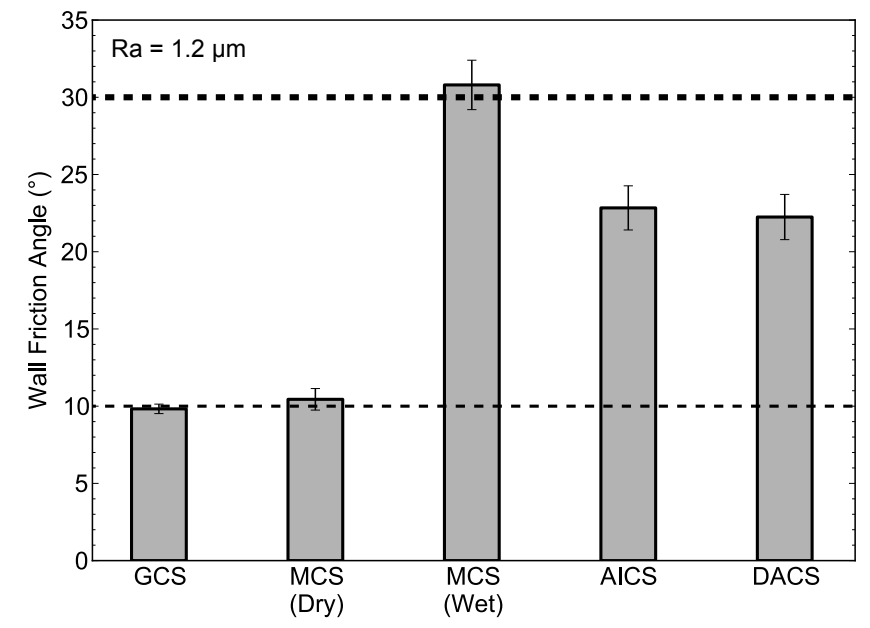

Figure 6: Average wall friction angles $(\mathrm{Ra}=1.2 \mu \mathrm{m})$ for the preprocessed corn stover feedstocks across consolidation normal stresses of 3,9 , and $15 \mathrm{kPa}$.

of applied normal stress, effective angle of internal friction $\left(\phi_{e}\right)$, unconfined yield strength $\left(f_{C}\right)$, major principal stress $\left(\sigma_{1}\right)$, and wall friction angle $\left(\phi_{w}\right)$ were used in Jenike's hopper analysis. It is worth noting that Jenike's hopper design method can sometimes produce irrational values for the size of a hopper opening, as his analysis relies heavily on where the flow function intersects the unconfined yield stress $\left(f_{c}\right)$ axis. Poor-flowing materials with a steep flow function will intersect the $f_{c}$ axis near the origin, resulting in an undersized hopper opening. Free-flowing materials with relatively flat flow functions, on the other hand, will result in large $f_{c}$ axis intercept values, leading to larger than necessary hopper openings [34]. Therefore, Jenike's hopper design protocol should be applied with caution and its results may not reflect true or suitable hopper design. However, if properly applied, Jenike's design methodology can be used as a relative assessment of material hopper discharge.

The calculated maximum hopper half angle $(\alpha)$ for the corn stover feedstocks varied from 16 to $36^{\circ}$ (right axis, Figure 7). Commonly, a hopper half angle of $20^{\circ}$ is often used as a rule of thumb for achieving mass flow of powders [34]. However, a hopper half angle of $20^{\circ}$ is inadequate for the wet or chemically impregnated corn stover materials, MCS (wet), AICS, and DACS, which require $\alpha$ values between 16 to $18^{\circ}$. The hopper half angles 


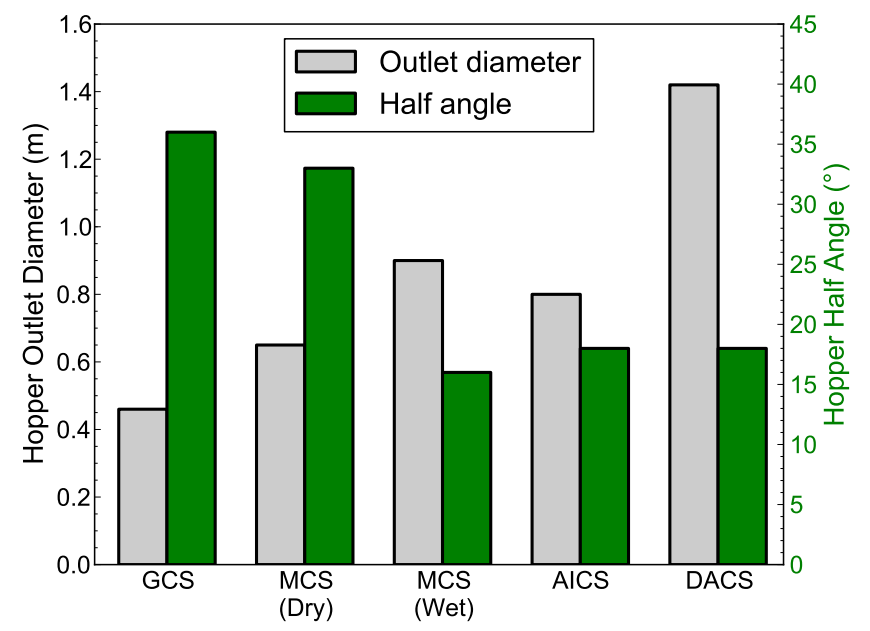

Figure 7: Theoretical minimum hopper outlet diameter (left axis) and maximum hopper half angle (right axis) to achieve mass flow during discharge of the examined preprocessed corn stover feedstocks.

for the two dry corn stover samples, GCS and MCS (dry), were $36^{\circ}$ and $33^{\circ}$, respectively, and should be easily discharged from a hopper with an $\alpha$ of $20^{\circ}$.

The minimum hopper outlet diameter $(B)$, which can be a less reliable metric than $\alpha$, ranged from 0.46 to $1.42 \mathrm{~m}$ for the preprocessed corn stover materials (left axis, Figure 7). The $B$ values for the GCS and MCS (dry) corn stover samples were 0.46 and $0.65 \mathrm{~m}$, respectively. The calculated hopper diameters for the MCS (wet) and AICS feedstocks were correspondingly 0.90 and $0.80 \mathrm{~m}$. The DACS material, on the other hand, had an estimated $B$ value of $1.42 \mathrm{~m}$, which was the largest required hopper opening for all of the preprocessed corn stover materials.

\section{Conclusions}

The compressibility, flow properties, and wall friction angles were measured for five preprocessed corn stovers: ground (GCS), milled (MCS (dry) and MCS (wet)), acid impregnated (AICS), and deacetylated (DACS). Of the tested samples, the ground corn stover was the least compressible and most flowable material. The deacetylated stover, on the other hand, was the most compressible and least flowable of the examined stovers. All of the impregnated corn stovers (wet, acid, and deacetylated) had elevated wall friction 
angles and reduced flow indices (excluding AICS). The reduced flowabilities and enhanced compressibilities and wall friction angles of the "wetted" corn stovers indicate the potential for additional feeding and handling issues; which was corroborated via theoretical hopper design calculations. All of the "wetted" materials (MCS (wet), AICS, and DACS) required larger hopper outlet diameters and steeper hopper walls (in theory) than the dry stovers (GCS and MCS (dry)), suggesting that feedstock preprocessing can significantly impact the design and operation of solids-handling systems.

Continuous feeding of biomass into, through, and out of reactors is essential for optimal conversion and for avoiding costly process stoppages. Moving forward, the methods and analysis used here can be applied to other lignocellulosic feedstocks to evaluate how preprocessing strategies impact their flowability. However, every feedstock is unique, and the relationships between preprocessing and flowability will be highly dependent on the nature of the feedstock (e.g., lignin content and structure, crystallinity, fiber content, etc.). Therefore, the feeding and handling of a potential feedstock must be evaluated (not just material conversion and product yield) when assessing the economic feasibility of a given pretreatment strategy.

\section{Acknowledgments}

This work was funded by the U.S. Department of Energy under Contract No. DE-AC36-08-GO28308 with the National Renewable Energy Laboratory and through the Office of the Biomass Program. The authors thank Allison E. Ray and Neal A. Yancey (INL) for supplying the milled and ground corn stovers for this study. The U.S. Government and the publisher, by accepting the article for publication, acknowledges that the U.S. Government retains a nonexclusive, paid up, irrevocable, worldwide license to publish or reproduce the published form of this work, or allow others to do so, for U.S. Government purposes.

\section{Appendix A. Hopper Design Calculations}

The discharge of bulk solids from hoppers was classified by Jenike [21] into two major flow regimes: mass flow and funnel flow. Mass flow is when every particle in a storage vessel moves downward in unison towards the vessel opening (i.e., the "first-in, first-out" principle). Mass flow is considered the ideal flow pattern for most applications. Funnel flow or "rat-holing", 
on the other hand, is when only a portion of the solids (typically near the vessel center) move downward during discharge and stagnant particle regions develop along the vessel walls. Funnel flow can be problematic and can commonly lead to material loss and/or degradation, unpredictable discharge patterns, flooding, and particle segregation (to name a few) [35]. However, if a hopper is designed properly, funnel flow can be avoided entirely [25, 35-37].

Along with categorizing the flow patterns of bulk solids, Jenike also developed a procedure for designing hoppers to ensure mass flow during discharge [21]. Jenike's methodology is still considered standard practice for hopper design [34]. A full description of Jenike's analysis is beyond the scope of this paper, but in general his approach involves determining two parameters: the flow function (FF) and flow factor (ff). FF depends solely on the shear strength of the bulk solids and describes the relationship between consolidating stress and shear strength of a material (i.e., unconfined yield stress vs. major principal stress; as plotted in Figure 5 in Section 3.3). Conversely, ff depends on the characteristics of the hopper (material of construction, shape, wall friction, etc.) as well as the solids, and describes the ability of a hopper to discharge consolidated (or compacted) solids via gravity. For mass flow to occur, ff must be stronger than FF (i.e., the applied hopper discharge stress must be greater than the unconfined yield strength of the material).

Jenike's design procedure allows for the determination of the maximum hopper half angle, $\alpha$ (the angle between the vertical vessel wall and the sloped hopper outlet) in order to avoid "rat-holes", and the minimum hopper outlet size, $B$, which prevents arching or bridging of material at the vessel opening. The first step in custom hopper design is to quantify the flow properties of the bulk solids. For proper design, a material's bulk density as a function of applied normal stress, effective angle of internal friction $\left(\phi_{e}\right)$, unconfined yield strength $\left(f_{C}\right)$, major principal stress $\left(\sigma_{1}\right)$, and wall friction angle $\left(\phi_{w}\right)$ must be measured. The effective angle of internal friction is needed for the design of gravity-driven hoppers because it determines the lateral (or outward) stress acting on the vessel walls [32]. The angle of wall friction, on the other hand, describes the strength of interaction between the bulk solids and the vessel wall material (the higher the angle the more difficult it is to move the particles along the wall surface). The unconfined yield stress is also an important parameter for hopper design because it indicates a material's arching strength.

Jenike's hopper design protocol involves the following steps: 


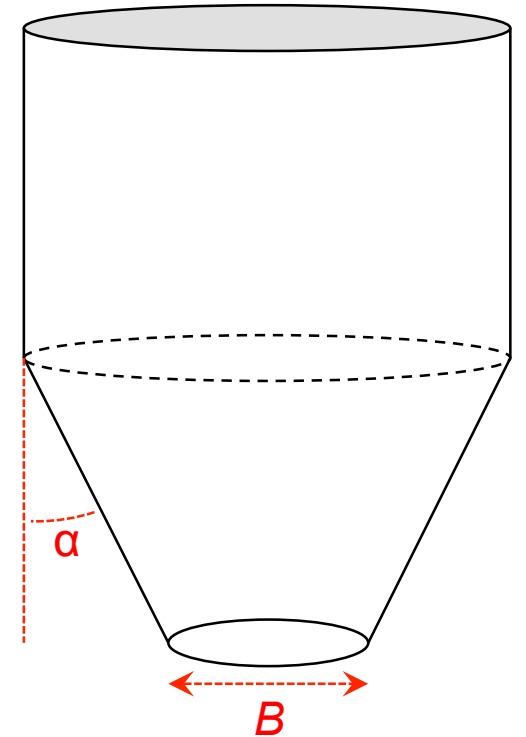

Figure A.8: Diagram of a conical hopper depicting the hopper half angle $(\alpha)$ and hopper outlet diameter $(B)$.

1. Obtain values of the effective angle of internal friction $\left(\phi_{e}\right)$ and wall friction angle $\left(\phi_{w}\right)$ and use them to calculate the hopper half angle $(\alpha)$ and flow factor (ff); Jenike published charts that relate $\phi_{e}$ and $\phi_{w}$ to both $\alpha$ and $\mathrm{ff}$ (mathematical representations of these charts are now available [38]).

2. Then determine the critical applied stress $(C A S)$ from the intersection of the measured flow function and calculated flow factor lines. The flow factor line is a straight line through the origin with a slope equal to $1 /$ ff.

3. Next, calculate the minimum hopper outlet size $(B)$ using values of $C A S$, hopper half angle $(\alpha)$, and bulk density $\left(\rho_{b}\right)$. The outlet diameter for a conical hopper, $B$, is given by:

$$
B=\frac{H(\alpha) C A S}{\rho_{b} g},
$$

$$
H(\alpha)=2+\frac{\alpha}{60},
$$

where $g$ is the gravitational constant. The bulk density must correspond to the consolidating stress at the hopper outlet. 


\section{References}

[1] Babu SP, Whaley TP. IEA biomass thermal gasification project. Biomass Bioenerg. 1992;2(1-6):299-6. International Energy Agency Bioenergy Agreement Progress and Achievements 1989-1991.

[2] Cummer KR, Brown RC. Ancillary equipment for biomass gasification. Biomass Bioenerg. 2002;23(2):113-28.

[3] Dai J, Cui H, Grace JR. Biomass feeding for thermochemical reactors. Prog Energy Comb Sci. 2012;38(5):716-36.

[4] Edwards D. Scaling Up Bioenergy Technologies. Chem Eng Prog. 2015;111(3):58-1.

[5] Fasina OO. Flow and physical properties of switchgrass, peanut hull, and poultry litter. Trans ASABE. 2006;49(3):721-8.

[6] Chevanan N, Womac AR, Bitra VSR, Yoder DC, Sokhansanj S. Flowability parameters for chopped switchgrass, wheat straw and corn stover. Powder Tech. 2009;193(1):79-6.

[7] Zhou B, Ileleji KE, Ejeta G. Physical property relationships of bulk corn stover particles. Trans ASABE. 2008;51(2):581-90.

[8] Ileleji KE, Zhou B. The angle of repose of bulk corn stover particles. Powder Tech. 2008;187(2):110-18.

[9] Samaniuk JR, Scott CT, Root TW, Klingenberg DJ. Rheological modification of corn stover biomass at high solids concentrations. J Rheol. 2012;56(3):649-65.

[10] Gil M, Schott D, Arauzo I, Teruel E. Handling behavior of two milled biomass: SRF poplar and corn stover. Fuel Process Tech. 2013;112:76-5.

[11] Miccio F, Barletta D, Poletto M. Flow properties and arching behavior of biomass particulate solids. Powder Tech. 2013;235(0):312-21.

[12] Crawford NC, Ray AE, Yancey NA, Nagle N. Evaluating the pelletization of "pure" and blended lignocellulosic biomass feedstocks. Fuel Process Tech. 2015;140:46-6. 
[13] Yancey NA, Wright CT, Conner CC, Tumuluru JS. Optimization of Preprocessing and Densification of Sorghum Stover at Full-Scale Operation. Proc ASABE, 2011 Annu Int Meet. 2011;.

[14] Schell D, Farmer J, Newman M, McMillan J. Dilute-sulfuric acid pretreatment of corn stover in pilot-scale reactor - Investigation of yields, kinetics, and enzymatic digestibilities of solids. Appl Biochem Biotech. 2003;105:69-85.

[15] Tucker MP, Kim KH, Newman MM, Nguyen QA. Effects of temperature and moisture on dilute-acid steam explosion pretreatment of corn stover and cellulase enzyme digestibility. Appl Biochem Biotech. 2003;105(1$3): 165-77$.

[16] Shekiro I Joseph, Kuhn EM, Nagle NJ, Tucker MP, Elander RT, Schell DJ. Characterization of pilot-scale dilute acid pretreatment performance using deacetylated corn stover. Biotech Biofuels. 2014;7(1).

[17] Trottier R, Dhodapkar S. A Guide to Characterizing Particle Size and Shape. Chem Eng Prog. 2014;110(7):36-6.

[18] International Organization for Standardization. ISO Standard 92762:2014 - Representation of results of particle size analysis - Part 2: Calculation of average particle sizes/diameters and moments from particle size distributions; 2014.

[19] Freeman R. Measuring the flow properties of consolidated, conditioned and aerated powders - A comparative study using a powder rheometer and a rotational shear cell. Powder Tech. 2007;174(1-2):25-3.

[20] Freeman RE, Cooke JR, Schneider LCR. Measuring shear properties and normal stresses generated within a rotational shear cell for consolidated and non-consolidated powders. Powder Tech. 2009;190(1-2):65-9.

[21] Jenike AW. Storage and flow of solids. Salt Lake City, Utah: Bull. Utah Eng. Exp. Stat; 1964.

[22] Carson JW, Wilms H. Development of an international standard for shear testing. Powder Tech. 2006;167(1):1-9.

[23] Tomas J, Schubert H. Particle characterization. Partec. 1979;79:301-19. 
[24] Chen X, Shekiro J, Elander R, Tucker M. Improved Xylan Hydrolysis of Corn Stover by Deacetylation with High Solids Dilute Acid Pretreatment. Ind Eng Chem Res. 2012;51(1):70-6.

[25] Chen P, Yuan Z, Shen X, Zhang Y. Flow properties of three fuel powders. Particuology. 2012;10(4):438-43.

[26] Camesasca L, Ramirez MB, Guigou M, Ferrari MD, Lareo C. Evaluation of dilute acid and alkaline pretreatments, enzymatic hydrolysis and fermentation of napiergrass for fuel ethanol production. Biomass Bioenerg. 2015;74(0):193-1.

[27] Agbor VB, Cicek N, Sparling R, Berlin A, Levin DB. Biomass pretreatment: Fundamentals toward application. Biotech Adv. 2011;29(6):67585 .

[28] Balat M, Balat H, Oz C. Progress in bioethanol processing. Prog Energ Comb Sci. 2008;34(5):551-73.

[29] Kumar P, Barrett DM, Delwiche MJ, Stroeve P. Methods for Pretreatment of Lignocellulosic Biomass for Efficient Hydrolysis and Biofuel Production. Ind Eng Chem Res. 2009;48(8):3713-29.

[30] Barbosa-Canovas GV, Juliano P. Compression and compaction characteristics of selected food powders. vol. 49. New York, NY: Kluwer Academic Plenum Publishers; 2005.

[31] Mani S, Tabil L, Sokhansanj S. Grinding performance and physical properties of wheat and barley straws, corn stover and switchgrass. Biomass Bioenerg. 2004;27(4):339-52.

[32] Ganesan V, Rosentrater KA, Muthukurnarappan K. Flowability and handling characteristics of bulk solids and powders - A review with implications for DDGS. Biosyst Eng. 2008;101(4):425-35.

[33] Puri V. Characterizing powder flowability. Chem Process. 2002;65:2942.

[34] Fitzpatrick JJ, Barringer SA, Iqbal T. Flow property measurement of food powders and sensitivity of Jenike's hopper design methodology to the measured values. J Food Eng. 2004;61(3):399-5. 
[35] Johanson J. Troubleshooting bins, hoppers and feeders. Chem Eng Prog. 2002;98(4):24-6.

[36] Purutyan H, Pittenger B, Carson J. Solve solids handling problems by retrofitting. Chem Eng Prog. 1998;94(4):27-39.

[37] Schulze D. Powders and Bulk Solids: Behavior, Characterization, Storage and Flow. 1st ed. Springer - Verlag Berlin Heidelberg; 2008.

[38] McGlinchey D. Characterisation of Bulk Solids. Wiley; 2009. 